\title{
Does information change German consumers' attitudes about genetically modified food?
}

\section{Journal Article}

Author(s):

Wüpper, David Johannes (iD; Wree, Philipp; Ardali, Goezde

Publication date:

2019-02

Permanent link:

https://doi.org/10.3929/ethz-b-000275765

Rights / license:

In Copyright - Non-Commercial Use Permitted

Originally published in:

European Review of Agricultural Economics 46(1), https://doi.org/10.1093/erae/jby018 


\title{
Does information change German consumers' attitudes about genetically modified food?
}

\author{
David Wuepper*, ${ }^{*}$, Philipp Wree ${ }^{*}$ and Goezde Ardali ${ }^{*}$ \\ ${ }^{\dagger}$ ETH Zurich, Agricultural Economics and Policy Group, Switzerland; \\ ${ }^{\ddagger}$ Technical University Munich, Production and Resource Economics, \\ Germany
}

Received April 2017; editorial decision May 2018; final version accepted May 2018

Review coordinated by Jack H.M. Peerlings

\begin{abstract}
We use a choice experiment to investigate attitude heterogeneity regarding genetically modified food and how it is affected by the provision of balanced information. For the analysis, we use a generalised multinomial and a latent class logit. The consumers who are more accepting of genetic modifications are younger, less educated and less concerned about their nutrition. The average effect of our provided information is negligible. However, the initially less opposed become slightly more opposed. Our results thus do not support the view that a lack of information drives consumer attitudes. Instead, attitudes seem to mostly reflect fundamental preferences. We discuss implications for research and policy.
\end{abstract}

Keywords: choice experiment, genetically modified bread, knowledge and preferences, attitudes and information

JEL classification: D12, D83

\section{Introduction}

Genetically modified (GM) food products are the subject of much controversy. According to the Eurobarometer for Biotechnology 2010, 57 per cent of European (EU 25) citizens are generally not willing to support GM foods (Gaskell et al., 2010). In Germany, according to a survey by the research institute (Forsa, 2014), 70 per cent of citizens deem no application of GM technology in food as either very important or even necessary. An open question is whether consumers are well informed about GM technology and whether more knowledge would positively affect acceptance. We conducted a labelled choice experiment (CE) with different breads, one of them containing 'functional' GM wheat. In this context, functional refers to added benefits 
such as a prolonged shelf-life, added micro-nutrients or more fibre. We consider GM bread with functional attributes because some consumer resistance to GM crops and products may simply result from a lack of benefits to the consumer (Emberger-Klein, Zapilko and Menrad, 2016).

On a fundamental level, choices and attitudes of consumers are a function of their preferences and beliefs (Manski, 2004; Lusk, Schroeder and Tonsor, 2014). For both policy makers and researchers, it is of interest to know whether choices and attitudes are better explained by differences in beliefs or preferences. If differences in beliefs are at play, disseminating information can affect consumers' choices and has the potential to improve social welfare (Lusk et al., 2004). However as Lusk et al. (2004) describe 'Although it is often argued that consumer education will improve acceptance of biotechnology, whether and to what extent information dissemination might affect consumers' attitudes towards GM food is largely unknown'.

To contribute to this literature, we investigate the effect of balanced information (that we provided) on the observed bread choices of German consumers in a CE. This allowed us to investigate who is most and least accepting of GM bread, who responds how to our provided information about the risks and benefits of GM and to estimate the overall effect of our provided information on the willingness to pay (WTP) for bread containing GM wheat. More specifically, we conducted a labelled CE in which German consumers were asked to indicate which bread they would chose when given the choice between different conventional, organic and GM breads (the latter often with added nutrients, more fibre or a prolonged shelf-life). Before we began our experiment, we asked the respondents about their attitudes and their openness to try GM. We then conducted the first half of our CE, paused to test the respondents' knowledge, provided balanced information about the risks and benefits of GM and then continued with the second half of the CE. By providing the information about GM ourselves, we avoided the problem of endogenous knowledge, e.g. due to different degrees of interest. Because interactions between endogenous and exogenous variables remain exogenous, we could further analyse inter-individual heterogeneity with regard to our treatment.

The motivation for testing the effect of provided information is that consumers might hold erroneous beliefs about a product, which could imply that their choices do not match their fundamental preferences (Manski, 2004). Possible information effects include:

- Providing balanced information could make attitudes and choices symmetrically more moderate. Learning could mitigate extreme beliefs and thus increase WTP for those initially more opposed to GM and decrease WTP for those initially more open towards GM.

- Providing balanced information could also make attitudes and choices symmetrically more extreme, e.g. there could be confirmatory bias (Rabin and Schrag, 1999). In this case, respondents would interpret our balanced information as supporting their initial beliefs. Initially, more pro-GM 
consumers would become less concerned about the risks of GM and increase their WTP. Initially, more contra-GM consumers would become more concerned about the risks of GM and decrease their WTP.

- There could simply be a homogenous increase or decrease in WTP, or no effect at all.

- Finally, the effect could be asymmetric, either only (or stronger) affecting those who were initially more opposed or more open.

In the literature, all four hypotheses have received empirical support (see Section 2), although they are contradictory. The main contributions of our study are, then, an augmented understanding of attitude heterogeneity regarding GM food technology, its sources and, most importantly, how it changes in response to the dissemination of balanced information. Doing so, we also explicitly consider the effect of adding benefits to the GM alternative (functional attributes). Methodologically, we are able to distinguish between preference and scale heterogeneity among the consumers, which are confounded in many discrete choice models, including the popular mixed logit. Scale heterogeneity arises when some consumers choose more randomly and others choose more deterministically (Fiebig et al., 2010; Wuepper, 2017).

We find that consumers who are generally more accepting of genetic modifications are younger, less educated and less concerned about their nutrition. The overall effect of our provided information then is very limited, but the initially less opposed become slightly more opposed. Thus, our main result is that we neither find any evidence for a positive effect of information on GM acceptance nor do we find any evidence for a confirmatory bias. Regarding the functional attributes that we added to the GM bread, we find a positive WTP for an increased shelf-life throughout our specifications but the WTP for added nutrients or fibre is not always statistically significant. As a further analysis shows, this is because only a share of the consumers has an appreciation of such functional attributes. Regarding our econometric specifications, we find that the generalised multinomial logit (GMNL) performs superior to simpler models, such as mixed or latent class logit (LCL) models. This is because there is not only preference, but also scale heterogeneity (always significant at any significance level).

In the next section, we briefly discuss the literature to which we aim to contribute (Section 2). We then describe our analytical framework and data (Section 3), before we come to our results (Section 4) and a discussion and conclusion (Section 5). Additional information and robustness checks are included in an appendix (in supplementary data at ERAE online).

\section{Literature}

Various factors have previously been identified to affect consumer attitudes about GM food. These include especially education, income, trust, knowledge and information (Costa-Font, Gil and Traill, 2008; Hess et al., 2016). Interestingly, the direction of the effects is not fully consistent (Lusk et al., 
2005). Onyango, Schilling and Nayga Jr (2004), Cuite, Aquino and Hallman (2005), Baker and Burnham (2001) and Costa-Font and Mossialos (2007) all find that individuals who (perceive to) know more about GM to have a more positive attitude towards GM technology. Boccaletti and Moro (2000) argue that knowledge decreases the uncertainty about GM and thus increases WTP. However, McCluskey et al. (2003) find that more knowledge decreases WTP. Wunderlich and Gatto (2015) describe how some knowledge dimensions are positively and some are negatively associated with acceptance.

In general, however, it is not clear whether all correlations between knowledge, attitudes and WTP can be meaningfully interpreted as causal. The attitudes and preferences of the consumers plausibly affect their interest in gaining more knowledge, which suggest the danger of reverse causality and omitted variable bias. This concern is supported by the finding of Christoph, Bruhn and Roosen (2008) that both GM supporters and opponents are more knowledgeable than individuals with neutral or uncertain attitudes. Exogenous variation in an individual's knowledge is required for identification. Rousu et al. (2002) find that experimentally providing consumers with negative information reduces their WTP, providing them positive information increases it and providing balanced information reduces it (the negative effect of balanced information is about 70 per cent of the effect of negative information). Similarly, Depositario et al. (2009) find that positive and negative information about Golden Rice influence respondents' attitudes positively and negatively, respectively. Consistent with these findings, Lusk et al. (2004) find that information about benefits of GM crops decreases the amount of money consumer demand to consume GM food in the USA, England and France. The magnitude of the effect is dependent on the degree of prior knowledge (higher for those who perceived to have been less informed before). Scholderer and Frewer (2003) experimentally provided consumers in Denmark, Germany, Italy and the UK with objective and balanced information about GM and find no effect on behaviour and a negative effect on consumer's attitudes towards GM. McFadden and Lusk (2015) point out that the assimilation of scientific information about GM foods depends on the individual's prior beliefs. It is thus likely that differences in beliefs and preferences are to some extent a function of differences in culture, public debates and economic development (Springer et al., 2002). Consistent with this, Moon and Balasubramanian (2001) find that UK consumers are more opposed to GM than consumers in the USA and House et al. (2005), Huffman and Rousu (2006) and Frewer et al. (2013) find that Europeans are more GM averse than North American or Asian consumers. However, in a meta-analysis of 214 different studies, Hess et al. (2016) also report about the varying evaluation of GM food in different countries. They find that studies in the European Union (EU) ask more often about perceived riskiness than in other parts of the world, which may bias findings. When study focus is controlled for, EU consumers no longer appear more GM averse than others (Hess et al. 2016). In addition to regional heterogeneity, Hess et al. (2016) identify average income, food product characteristics, the characteristics of the 
biotechnology, knowledge and the information provided in the survey as explanatory factors for GM attitudes. Recently, Butkowski et al. (2017) conducted a laboratory experiment in Germany, investigating the risk perceptions of different types of genetic engineering. They find that the level of perceived risk is significantly higher for food than bioenergy, which is mostly driven by higher perceived health risks.

\section{Research design}

In this section, we begin by a brief outline of our experimental procedure (3.1), followed by a description of how we designed our choice sets (3.2), how we sampled (3.3), descriptive statistics (3.4) and an explanation of our analytical framework (3.5).

\subsection{A brief outline of our experiment}

The fundamental idea of the $\mathrm{CE}$ is to simulate a market situation in which a consumer indicates her preferred choice from a set of described alternatives (Louviere, Hensher and Swait, 2000). By repeating such a 'simulated market', the researcher can e.g. identify the marginal effects of changes in the alternatives' attributes and sometimes also those of consumer characteristics or interactions between product attributes and consumer characteristics (when these characteristics are plausibly exogenous). Before the $\mathrm{CE}$, we explained to the respondents how the $\mathrm{CE}$ would work and we provided a choice card for practise (see Figure 1 for an example choice card). We made sure the respondents understood well how a $\mathrm{CE}$ works and thus to avoid learning effects during the experiment (Carlsson, Mørkbak and Olsen, 2012). Respondents were also asked about their views and attitudes regarding GM and about their basic demographic characteristics. The respondents were then asked to fill out a first set of four choice cards. Afterwards, they were asked about their consumption habits and responsibilities (see Appendix B in supplementary data at ERAE online), as well as knowledge questions about GM crops. Subsequently, they were provided with balanced information about GMOs (unrelated to the knowledge questions). Hereafter, the CE continued with the second set of

\begin{tabular}{|c|c|c|c|c|}
\hline Alternative Breads & GM & Conventional & Organic & \multirow{5}{*}{$\begin{array}{c}\text { neither } \\
\text { of } \\
\text { these } \\
\text { breads }\end{array}$} \\
\hline Functional Attribute & $\begin{array}{l}30 \% \text { more dietary } \\
\text { fibre }\end{array}$ & - & - & \\
\hline Flour Type & whole grain & regular & whole grain & \\
\hline Sales Location & $\begin{array}{c}\text { baking station in } \\
\text { supermarket }\end{array}$ & $\begin{array}{c}\text { baking station in } \\
\text { supermarket }\end{array}$ & bakery & \\
\hline Price & $2.50 € / 750 \mathrm{~g}$ & $2.75 € / 750 \mathrm{~g}$ & $3.25 € / 750 \mathrm{~g}$ & \\
\hline $\begin{array}{l}\text { Which bread would you } \\
\text { choose? } \\
\text { (Please tick only one box) }\end{array}$ & & & & \\
\hline
\end{tabular}

Fig. 1. Example choice card (translated, original in German). 
four choice cards. At the end, they were asked how important they considered each attribute in the $\mathrm{CE}$ so we could investigate attribute non-attendance (ANA) (Scarpa et al., 2009a), and we asked the respondents how much they trusted our information, how well they understood it and whether they changed their mind about GMOs during our experiment.

\subsection{Design of the choice sets}

Desirable properties of CE designs include orthogonality (levels of attributes appear with equal frequency with each level of each other attribute), item balance (each alternative appears equally often in each choice set with every other alternative), level balance (each level of each attribute appears with equal frequency), minimum overlap (as few level overlaps of each attribute in each choice set as possible) and utility balance (similar choice probabilities for the alternatives in a choice set) (Viney, Savage and Louviere 2005). However, there often is a trade-off between statistical efficiency (which is increased with the above named properties) and response efficiency (which can suffer from the above named properties) (Louviere et al. 2002). We used SPSS Conjoint to create a fractional factorial design with 32 different choice sets. The CE design was evaluated using the A- and D-efficiency criterion. Our initial design achieved perfect scores of 100, suggesting high statistical efficiency. However, statistical efficiency is not everything (Reed Johnson et al. 2013). In particular, our initial design produced choice cards with dominated alternatives (e.g. a GM bread for the highest price and without functional attributes). When we optimised our design with regard to response efficiency, we lowered the A- and D-efficiencies to 70 per cent and 84 per cent, respectively. These rather low scores come from the fact that only GM bread has functional attributes, so that not all alternatives have the same number of attributes. Computing the efficiencies without the functional attributes leads to scores of 99 per cent for both criteria. A shortcoming of our design is that it only considers main effects and neglects possible interactions between attribute levels. According to Lusk and Norwood (2005), this design allows for the estimation of unbiased values but designs that incorporate interactions lead to more statistical precision. Viney, Savage and Louviere (2005) advise to use an $\mathrm{L}^{\wedge} \mathrm{MA}$ design to achieve a higher statistical precision, but also find no statistically significant parameter differences between different designs (they tested a standard orthogonal main effects design, a design that aims for utility balance and a design that combines alternatives randomly).

Table 1 provides an overview of the attribute levels in our CE. Importantly, we improved the attractiveness of GM bread with increased functional attributes compared to the other alternatives, such as longer shelflife or more nutrients. We also chose alternative specific prices in order to construct a realistic market situation and we allowed the consumer not to 'buy' any bread just as they could in the real market. The CE was designed 
Table 1. CE attributes and levels for the different breads

\begin{tabular}{lllll}
\hline & GM & Conventional & Organic & Opt out \\
\hline $\begin{array}{c}\text { Functional } \\
\text { attribute }\end{array}$ & $\begin{array}{c}\text { Doubled shelf-life } 30 \% \\
\text { more dietary fibre doubled } \\
\text { iron and enhanced } \\
\text { vitamin A content }\end{array}$ & None & None & None \\
& & & & \\
Flour type & Whole grain regular & Whole grain & Whole grain & None \\
& & regular & regular & \\
Location & Baking station in & Baking station in & Baking station in & None \\
& supermarket bakery & supermarket & supermarket & \\
& & bakery & bakery & \\
Price & $1.75 € / 750 \mathrm{~g}$ & $1.75 € / 750 \mathrm{~g}$ & $3.25 € / 750 \mathrm{~g}$ & None \\
& $2.50 € / 750 \mathrm{~g}$ & $2.25 € / 750 \mathrm{~g}$ & $3.75 € / 750 \mathrm{~g}$ & \\
& $3.25 € / 750 \mathrm{~g}$ & $2.75 € / 750 \mathrm{~g}$ & $4.25 € / 750 \mathrm{~g}$ & \\
& $4.00 € / 750 \mathrm{~g}$ & $3.25 € / 750 \mathrm{~g}$ & $4.75 € / 750 \mathrm{~g}$ & \\
\hline
\end{tabular}

Source: Authors' summary.

Table 2. Functional attributes of the GM bread

\begin{tabular}{llll}
\hline Attribute & Level & GM bread & Traditional bread \\
\hline Shelf-life & Doubled & 6 days & 3 days \\
Vitamin A content (per slice) & Enhanced & $5 \%$ of RDA* & $0.05 \%$ of RDA* \\
Iron content (per slice) & Doubled & $30 \%$ of RDA* & $15 \%$ of RDA* \\
Dietary fibre (per slice) & $30 \%$ more & $15 \%$ of RDA* & $11 \%$ of RDA* \\
\hline
\end{tabular}

*RDA: recommended daily allowance (Calculations were done based on the assumption of 1 slice of bread is $50 \mathrm{~g}$ ).

to closely resemble the real market (e.g. the price ranges were informed by the actual price ranges found in bakeries, supermarkets and stores). Because there is no available data for GM bread in Germany and to include additional attribute values if necessary, we also conducted pilot studies with different consumers before the actual study began. Especially important was to find out the full price range that consumers might be willing to pay (Hanley, Adamowicz and Wright, 2005; Ratcliffe, 2000; Carlsson and Martinsson, 2008).

The functional attributes of the breads were explained at the beginning of the $\mathrm{CE}$ to make sure every respondent understood what was offered. Table 2 provides an overview of how 'doubled shelf-life', 'doubled iron and enhanced vitamin A content' or '30 per cent more dietary fibre' were exactly defined. Each respondent was first shown in Table 2 and was then asked how likely she would be to buy GM bread if it were available in the market. The possible answers ranged from very unlikely to very likely. Then, they were shown a paragraph of 'cheap talk', which reminded participants about the danger of hypothetical bias and how they should approach the following choices (Carlsson, Frykblom and Lagerkvist, 2005). 
Table 3 shows the knowledge questions we asked our respondents. Table 4 shows the information we provided. We were especially careful in selecting positive and negative statements to make our experimentally provided information as balanced as possible and not bias the respondents in one or the other direction. Respondents were not informed about their score in the knowledge questions, in order to avoid confounding effects, such as changed subjective knowledge.

Table 3. Statements to test knowledge

Statement

1. The most GM crop in the world is the soybean

2. Currently, there is no commercially grown GM wheat in the world

3. 'Golden Rice' is currently available on the market

4. The commercial cultivation of GM crops is prohibited in Germany
Answer categories

\begin{tabular}{|c|c|c|}
\hline True & False & Do not know \\
\hline$\overline{\text { True }}$ & False & Do not know \\
\hline True & False & Do not know \\
\hline True & $\overline{\text { False }}$ & Do not know \\
\hline
\end{tabular}

Note: The correct answer to the statement is underlined. Answers from James (2010), United States Department of Agriculture (2016), Steur et al. (2015) and Bundesministerium für Ernährung und Landwirtschaft (2016).

Table 4. Information sheet (translated, original in German)

Health

-According to the World Health Organization (WHO), all commercially available GM crops have passed their risk assessments. These assessed possible impacts on human health and the environment WHO (2014). However, there are studies with mammals that found toxic reactions in liver, kidneys and digestive system de Vendômois et al. (2009) and Trabalza-Marinucci et al. (2008)

-According to the 'International Life Science Institute', the DNA of GM crops is indistinguishable from regularly bred plants. A transfer of DNA from a GM plant to a human cell is highly unlikely Jonas et al. (2001)

Environment. - By using GM crops, in the first 15 years the USA have saved 500 Mio. $\mathrm{kg}$ in agro-chemicals. Just the saving from 2013 reduced $\mathrm{CO}_{2}$ emissions by 28 billion kg James (2014)

-Plants can be GM to produce a toxin as protection Niederhuber (2015). Studies have not found negative effects but there is a debate about how much evidence is necessary to conclude that GM crops are harmless in the long-term FAO (2004)

Nutrition -Through GM technology, the iron concentration in wheat can be increased by $75 \%$ Borg et al. (2009)

-The best-known GM crop is Golden Rice. This rice contains up to six micrograms of vitamin A per gram of rice (daily requirement is about $800 \mathrm{mg}$ ), whereas normal rice contains only traces of vitamin A Tang et al. (2009). This crop waits for commercial approval since 15 years ago De Steur et al. (2015) 


\subsection{Sampling}

The CE was conducted between June and September 2016 in the Munich metropolitan area in Germany. In a pilot study, it was found that GM bread would only be chosen 13 per cent of the time (i.e. in 13 per cent of the choice situations). According to Hensher, Rose and Greene (2010) the final sample should include 50 observations on the least popular alternative. This suggested a final sample size of about 400 consumers. Nine supermarkets and nine bakeries (organic and conventional) were selected randomly in different districts across Munich. Two thirds of the sampled sales locations were conventional ones, whereas the other third was organic. It should be noted that this ratio is representative of consumption patterns in Munich but it is higher in the rest of Germany.

In the selected locations, every third person was approached. If the person was unwilling to complete the survey, the proceeding person was asked. Furthermore, the survey was conducted on different days of the week and at different times of the week to ensure a random and representative sample.

Around 25 respondents from each bakery and supermarket completed the survey, yielding 415 responses in total. Five hundred and seventy-five individuals refused to complete the survey so the overall response rate was 41.92 per cent. Following the advice of Ison and Kontoleon (2014), the topic of the survey (i.e. GM food) was mentioned only after a respondent agreed to participate in the survey, thus refusals were not influenced by the questionnaire topic. Out of 415 surveys, 10 were discarded for violating the choice process in the survey. Three of these respondents chose more than one alternative and seven respondents did not complete their surveys. Moreover, eight respondents, who always chose the alternative opt-out, were excluded from the analysis in case they did not understand the choice process or did not want to give their true preferences to protest the survey. After discarding the unusable surveys, 397 surveys remained.

\subsection{Data}

Table 5 shows basic descriptive statistics about our data. The largest group of respondents is between 26 and 35 years old, employed and have a university degree. This suggests that our sample is younger and better educated than the average person in Munich. However, including or excluding sociodemographic variables does not affect our results at all. This suggests that our estimated conditional choice probabilities and conditional WTP estimates are externally valid. It is also well known that estimated, conditional choice probabilities are unaffected by the sampling scheme but the constants are biased when not interacted (Manski and Lerman, 1977). Since we are analysing interacted constants in our study, we did not worry about selection bias (Nizalova and Murtazashvili, 2016). However, the estimated class shares in our latent class approach and our descriptive statistics, including all market shares must be treated with caution. 
Table 5. Sample

\begin{tabular}{lcc}
\hline & Mean & SD \\
\hline Age (in years) & & \\
18-25 & 0.19 & 0.39 \\
$26-35$ & 0.38 & 0.48 \\
$36-45$ & 0.15 & 0.35 \\
$46-55$ & 0.13 & 0.34 \\
$56-65$ & 0.09 & 0.29 \\
$>65$ & 0.02 & 0.16 \\
Occupation (categories) & & \\
Employee & 0.52 & 0.49 \\
Worker & 0.03 & 0.17 \\
Government & 0.10 & 0.31 \\
Housewife & 0.05 & 0.23 \\
Retired & 0.03 & 0.18 \\
Self-employed & 0.06 & 0.24 \\
Student & 0.16 & 0.37 \\
Other & 0.01 & 0.09 \\
Education (levels) & & \\
PhD & 0.02 & 0.15 \\
University & 0.46 & 0.49 \\
Abitur (advanced) & 0.20 & 0.40 \\
Real (intermediate) & 0.22 & 0.41 \\
Haupt (basic) & 0.08 & 0.27 \\
\hline
\end{tabular}

Note: The German education system is divided in three levels of distinct length and difficulty. Having successfully completed the highest level (Abitur) is a requirement for University admission. SD, standard deviation.

Table 6. Knowledge, trust, understanding and change of mind

\begin{tabular}{llll}
\hline & Mean & SD & Max possible \\
\hline KNOW & 0.99 & 0.876 & 4 \\
SOY & 0.40 & 0.49 & 1 \\
BAN & 0.40 & 0.49 & 1 \\
RICE & 0.13 & 0.33 & 1 \\
WHEAT & 0.06 & 0.24 & 1 \\
Trust & 3.41 & 0.97 & 6 \\
Understood & 4.21 & 0.79 & 6 \\
Changed mind & 2.13 & 1.12 & 6 \\
\hline
\end{tabular}

Note: It can be seen that on average, 1 out of 4 knowledge (KNOW) questions was answered correctly, with the question on wheat (WHEAT) apparently being the most difficult, followed by the questions on rice (RICE), soy (SOY) and the ban (BAN) (see text above for these questions). It can also be seen that trust in our provided information was 3.4 out of 6 , perceived understanding was 4.2 out of 6 and perceived change of mind in response to this information was 2 out of 6 .

Table 6 shows further characteristics of the sampled consumers. KNOW is the average number of knowledge questions the consumers could answer correctly, which is about 1 . Overall, 36 per cent of the respondents could not answer any 
question correctly, 36 per cent could only answer one correctly, 22 per cent could answer two correctly, 6 per cent could answer three correctly and nobody was able to answer all our questions correctly (see Appendix A in supplementary data at $E R A E$ online). We chose the questions based on whether they could be clearly answered and their differing degree of difficulty. SOY expresses whether the first knowledge question could be answered correctly (i.e. soybean is the most GM crop in the world). Only 40 per cent of the respondents knew the answer. BAN expresses whether the second knowledge question could be answered correctly (i.e. commercial cultivation of GM crops is prohibited in Germany). About 40 per cent could answer this question correctly. RICE expresses whether the third knowledge question could be answered correctly (i.e. 'Golden Rice' is currently not available on the market). Only about 13 per cent knew this. Finally, WHEAT refers to whether the fourth knowledge question could be answered correctly (i.e. there is no commercially grown GM wheat in the world). Only about 6 per cent of the respondents knew the answer. Table 6 also shows that the respondents stated to have trusted our provided information on a Likert scale from 1 to 5 with 3.4 (average trust), understood it on the same scale with a 4.2 (high understanding) and the information did not change their mind (giving this 2 out of 5 points).

It is perhaps surprising that the respondents seem to know little about GM but also do not change their mind about it when provided with more information. However, it should be noted that the little information people have could be sufficient to match their attitude to their preference. Then, providing more information would only confirm their previous beliefs. Alternatively, behavioural economics literature is full of examples of how people ignore information or even interpret it as supporting whatever they initially believed (Rabin, 1998; Rabin and Schrag, 1999). It is also possible that they changed their mind but are not aware of this. Before we investigate these questions, we first explore who knows more about GM than others. Perhaps unsurprisingly, the older and better educated a respondent, the more the person knew about GM (Table 7).

As mentioned above, before the CE, we asked 'How likely would you buy GM bread, if it were available in the market?' on a Likert scale from 1 to 7. As Appendix A (in supplementary data at ERAE online) shows, the majority of respondents ( 71 per cent) indicated it is unlikely that they would buy GM bread, while 20 per cent of the respondents indicated less aversion. Furthermore, respondents were asked to evaluate statements about GM on a scale from 1 (=strong disagreement) to 5 (=strong agreement).

Regarding the perceived attributes of GM crops, Table 8 indicates that people are mostly concerned about the safety of GM and in particular any unforeseen, long-term effects. They are not convinced that GM helps to reduce $\mathrm{CO}_{2}$ emissions and they perceive GM breeding as unnatural compared to traditional plant breeding techniques. Even functional attributes are not a major selling point, as most consumers would prefer alternatives such as changing their diets in other ways.

Table 9 shows the 'market shares' of different breads, before and after respondents were provided information, in absolute terms and as percentage 
Table 7. Who knows more about GMOs than others?*

\begin{tabular}{|c|c|}
\hline & KNOW \\
\hline \multicolumn{2}{|l|}{ Education } \\
\hline $\mathrm{PhD}$ & $\begin{array}{l}0.867 * * * \\
(0.0548)\end{array}$ \\
\hline University & $\begin{array}{l}0.362 * * * \\
(0.0321)\end{array}$ \\
\hline Abitur & $\begin{array}{l}0.313 * * * \\
(0.0351)\end{array}$ \\
\hline Real & $\begin{array}{l}0.304 * * * \\
(0.0318)\end{array}$ \\
\hline \multicolumn{2}{|l|}{ Age } \\
\hline$>65$ years & $\begin{array}{l}0.817 * * * \\
(0.0824)\end{array}$ \\
\hline$>56$ years & $\begin{array}{l}0.401 * * * \\
(0.0347)\end{array}$ \\
\hline$>46$ years & $\begin{array}{l}0.0892 * * * \\
(0.0309)\end{array}$ \\
\hline$>36$ years & $\begin{array}{l}0.0747 * * \\
(0.0297)\end{array}$ \\
\hline$>26$ years & $\begin{array}{c}-0.222 * * * \\
(0.0241)\end{array}$ \\
\hline Controls & Occupation \\
\hline$R^{2}$ & 0.083 \\
\hline$N$ & 12,704 \\
\hline
\end{tabular}

Note: The table shows OLS regression coefficients from a regression of the number of correct answers on basic socio-demographic variables. The baseline categories are always the lowest level. See Table 5 for notes on Germany's education system. Significance levels are $10 \%(*), 5 \%(* *)$ and $1 \%(* * *)$.

Table 8. Statements about GMOs

\begin{tabular}{lrr}
\hline Statement & Mean & SD \\
\hline GM is safe & 2.20 & 1.14 \\
GM is toxic and/or carcinogenic & 3.05 & 1.09 \\
Functional GM foods are more nutritious than regular foods & 3.24 & 1.32 \\
Long-term effects of GM on the environment and human health are & 4.02 & 1.19 \\
$\quad$ uncontrollable & & \\
GM helps to reduce $\mathrm{CO}_{2}$ emissions and mitigate climate change & 2.96 & 1.30 \\
GM plants are unnatural & 4.21 & 1.15 \\
I would rather avoid bad eating habits than choose functional GM foods & 4.07 & 1.23 \\
\hline
\end{tabular}


Table 9. 'Market shares' of organic, conventional and GM bread

\begin{tabular}{lllll}
\hline & GM & Conv & Organic & None \\
\hline Before info & $1,056(16 \%)$ & $3,156(48 \%)$ & $1,500(24 \%)$ & $640(12 \%)$ \\
After info & $1,076(16 \%)$ & $3,108(48 \%)$ & $1,504(24 \%)$ & $664(12 \%)$ \\
\hline
\end{tabular}

Source: Authors' summary.

results. Overall, conventional bread was the most popular (48 per cent market share), followed by organic bread ( 24 per cent). The GM bread was the least popular alternative (16 per cent). As can be seen, our information provision did not affect overall market shares at all.

To investigate the effect of our provided information about GM technology on consumers with different initial attitudes, we created four variables. OPEN equals 1 if the respondent stated to be relatively more likely to try a GM bread if it were available (5, 6 and 7 on a scale from 1 to 7 ) and -1 otherwise (zero with dummy coding). OPPOSED equals 1 if the respondent stated to be relatively less likely to try a GM bread if it were available (1-3 on the same scale as above) and -1 otherwise (zero with dummy coding). POS equals 1 if the respondent agreed on average with more positive statements about GM food (e.g. GM is safe or GM helps to reduce $\mathrm{CO}_{2}$ emissions and mitigate climate change, see Table 8 ) and -1 otherwise (zero with dummy coding). NEG equals 1 if the respondent agreed on average with more negative statements (e.g. GM is toxic and/or carcinogen or long-term effects of GM on the environment and human health are uncontrollable) and -1 otherwise (zero with dummy coding).

An important issue is whether to use dummy or effects coding (Bech and Gyrd-Hansen, 2005; Hensher, Rose and Greene, 2015; Daly, Dekker and Hess, 2016). We find the same results with either coding scheme but report only the results from our analysis of effects coded data here, because it has advantages when using interaction effects. In our published data, both versions can be found and compared. Dummy coded variables indicate whether an alternative has a particular attribute level (yes $=1)$ or not $($ no $=0)$. As always with $K$ dummy variables, we can only include $K-1$ and the coefficients are then estimated in comparison to the omitted attribute level. With effects coding, one attribute level is additionally coded as -1 when absent, so that we do not interpret the estimated coefficients as comparisons to any omitted attribute level, but to the unweighted average of all levels. We will further explain the interpretation of our estimated coefficients in the next section.

\subsection{Analytical framework}

We are interested in modelling the bread choices of the consumers and whether experimentally provided information (i) generally affects choices and (ii) whether it effects everybody the same or not. 
Our main model in this study is the GMNL (Fiebig et al. 2010). We estimate:

$$
\begin{gathered}
\text { Choice }_{n j}=\mathrm{ASC}_{n j}+\beta_{n, 1} x_{j}+\beta_{2} z_{n}+\beta_{n, 3}\left(x_{j} * z_{n}\right)+\varepsilon_{n j} \\
n=1, \ldots, N ; j=1, \ldots, J
\end{gathered}
$$

where the left-hand side is the alternative $j$ person $n$ chooses and the righthand side variables are alternative specific constants for each alternative $\left(\mathrm{ASC}_{n j}\right)$, the effect of the alternatives' attributes $\left(\beta_{n, 1}\right)$, the effect of the consumers' characteristics $\left(\beta_{2}\right)$ and interactions between consumer characteristics and alternative attributes $\left(\beta_{n, 3}\right)$. An important advantage of the GMNL framework over its alternatives, such as the mixed or the LCL, is that the GMNL takes into account both preference and scale heterogeneity. The estimated coefficients are individual specific:

$$
\beta_{n}=\sigma_{n} \beta+\gamma \eta_{n}+(1-\gamma) \sigma_{n} \eta_{n}
$$

where $\sigma_{n}$ is a individual scaling parameter (giving greater weight to more deterministic choices and smaller weight to more random choices), $\beta$ is the average coefficient over all respondents, $\eta_{n}$ is the individual deviation of person $n$ from this average and $\gamma$ governs how the variance of residual taste heterogeneity varies with the scale in a model that includes both. It should be noted that when scale heterogeneity is not explicitly modelled, it is implicitly assumed to be absent and will practically be absorbed by the $\beta_{n}$, such that preference and scale heterogeneity are confounded.

To investigate the effect of information on the choice of bread and whether it differs between different consumers, we estimate versions of the following model:

$$
\begin{aligned}
& \text { Choice }_{n j}= \beta_{n, 1} I_{1}+\beta_{n, 2} I_{2}+\beta_{n, 3} I_{3}+\beta_{n, 4} \mathrm{GM}+\beta_{n, 5} \mathrm{CON}+\beta_{n, 6} \mathrm{ORG} \\
&+\beta_{n, 7} I \mathrm{NFO}+\beta_{n, 8} x_{j}+\varepsilon_{n j} \\
& I_{1}=\mathrm{INFO} \times \mathrm{OPEN} \times \mathrm{GM} \text { or INFO } \times \text { OPPOSED } \times \mathrm{GM}, \\
& I_{2}=\mathrm{INFO} \times \mathrm{GM} \text { and } \\
& I_{3}=\mathrm{OPEN} \times \mathrm{GM} \text { or OPPOSED } \times \mathrm{GM} .
\end{aligned}
$$

To simplify the interpretation of our results, we estimate all models in 'WTP-space' (Train and Weeks, 2005). This means that the cost coefficient is constrained to minus one, which expresses all other coefficients directly in WTP. ${ }^{1}$ Thus, instead of the choice probability Choice $_{n j}$ in equation (1) the left-hand side variable in our models is $\mathrm{WTP}_{n j}$, the respondents' WTP.

In addition to the main analysis, we also recover the individual specific preference parameters (as shown by Revelt and Train (2000)) and compute

1 Because the cost coefficient indicates the preference for money and the other coefficients indicate the preference for the bread attribute, the ratio between the coefficients is the WTP for the attribute. 
the variable Change, which expresses the effect of our provided information in absolute terms, i.e. how much choices changed, independently from its overall sign (whether WTP increased or decreased).

Finally, we also estimate a LCL model, which does not consider individual specific heterogeneity, but models heterogeneity at the level of groups that are created to be as homogenous as possible within and as heterogeneous as possible between each other. Thus, instead of equation (1), we simultaneous estimate the following two stages:

$$
\begin{gathered}
\text { Choice }_{n j}=\mathrm{ASC}_{\mathrm{c} j}+\beta_{\mathrm{c}, 1} x_{j}+\varepsilon_{\mathrm{cj}}, \quad \mathrm{c}=1, \ldots, \mathrm{C} ; j=1, \ldots, J \\
c=\delta z_{n}+\varepsilon_{n},
\end{gathered}
$$

where $c$ is the latent class in which a consumer is sorted into because of her preferences and $z_{n}$ are the respondents' characteristics that describe each latent class.

As a robustness check, we repeat some of our estimations with only the first four choice cards per respondent and an interaction term that tests whether choices significantly changed after the first two choice sets. This is an important test because we effectively identify the effect of our provided information by comparing whether choices change between the first four and the latter four choice sets because that is where respondents receive the information. As Carlsson, Mørkbak and Olsen (2012) show, if respondents do not perfectly understand the working of the $\mathrm{CE}$ beforehand, they might need the first two choice sets 'to practise', and one might find that choice patterns change during the experiment because of experience. If we do not find a change in choices between the first and the latter two choice sets, we can safely assume that there is no learning about the CE (which we expect because respondents practised the $\mathrm{CE}$ before it started). Then, a change in choices between the first four and the latter four cleanly identifies the treatment effect of information.

\section{Results}

Table 10 summarises the results of four specifications in which the dependent variable is the WTP for each kind of bread and its attributes. With a pseudo $R^{2}$ of 0.32 our models fit the data quite well (McFadden, 1973; Train, 2003).

It can be seen that consumers have a lower WTP for GM bread than for other breads, whereas WTP for organic and conventional bread is rather similar and much higher. It can also be seen that respondents who stated to be more open towards trying GM bread were indeed significantly more likely to choose a GM bread (specification 1), whereas respondents who stated to be less likely to choose GM bread were indeed significantly less likely to choose a GM bread (specification 2). Respondents who agreed with more positive or more negative statements (specifications 3 and 4, respectively) also behaved according to expectations. 
Table 10. Attitudes, information and WTP for GM bread

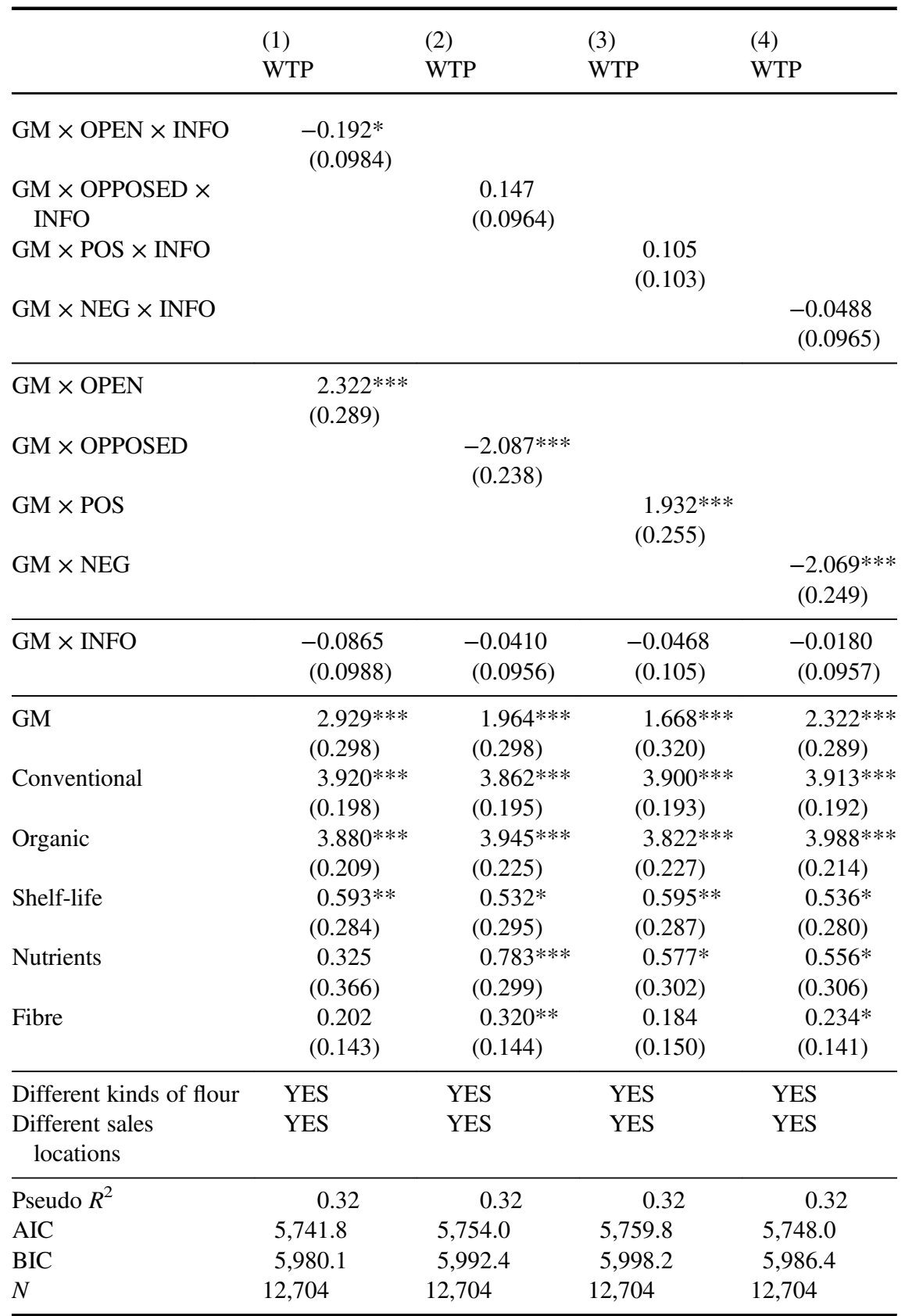

Note: The table shows GMNL estimated coefficients and standard errors in brackets. Significance levels are $10 \%$ $(*), 5 \%(* *)$ and $1 \%(* * *)$. The coefficients express the WTP for the attributes. Data are effects coded. The estimated scale and preference heterogeneity parameters can be obtained from the authors upon request. 
Our provided information only had a small, negative effect on the respondents initially a little more open towards GM bread (specification 1): These consumers' WTP sunk by 19 cents, but only significant at the 10 per cent level. The consumers who were initially more opposed towards GM bread tended towards becoming a little more open towards GM bread, but the effect is not statistically significant at any level. Regarding the functional attributes of the GM breads, the most robust WTP is estimated for an increased shelflife. Added nutrients and fibres were not always significant but tended towards a positive WTP.

We need to consider whether we can distinguish between the effect of our provided information and an ordering effect (e.g. respondents gaining experience with the $\mathrm{CE}$ and thus choices change because they better reflect actual preferences). In Appendix C (in supplementary data at ERAE online), we repeat the first two specifications (as we find a significant effect in one of them) but on a restricted sample that only includes choice sets that were answered before our treatment. As Carlsson, Mørkbak and Olsen (2012) show, learning is especially likely in the first two choice sets. We do not find any change in choices between the first and the latter two choice sets, which suggests that we succeeded in explaining the functioning of the CE to the respondents (including letting them practise with an example choice card). Thus, our interaction terms identify the effect of information.

We also considered ANA, i.e. how much the various attributes have actually been considered in the CE (Scarpa et al., 2009b, 2012). We use both reported ANA and a latent class approach in which we constrain to zero the coefficient for the attributes reported to be most ignored (Appendix D in supplementary data at ERAE online). The respondents reported that the functional attributes of the GM bread were most ignored and we estimate this to be the case by about 24 per cent of the respondents.

Since we are estimating individual specific coefficients, we can follow the approach of Revelt and Train (2000) and recover the individual specific choice parameters from the estimated preference distributions. After doing so, we can run a simple OLS regression on the variable CHANGE, which captures how much, but not in which direction, individuals changed their behaviour in response to our information sheet. More specifically, the variable is defined as the absolute value of the difference between the probability to choose a GM bread before and after having received the information about GM technology after half the CE. The regression of CHANGE on respondent characteristics allows us to investigate a few more interactions between characteristics of the respondents and our information sheet. Table 11 shows that initially more open consumers were more likely to change their mind (which we already saw above), whereas more opposed consumers, (those with more negative views about GM) and those with more knowledge about GM (those who could answer more of our questions correctly) were significantly less likely to change their mind during our experiment (Table 12). 
Table 11. Who changes their behaviour in response to additional information?

\begin{tabular}{lc}
\hline & CHANGE \\
\hline OPEN & $0.124^{* *}$ \\
OPPOSED & $(0.0554)$ \\
POS & $-0.110^{* *}$ \\
& $(0.0532)$ \\
NEG & 0.0644 \\
& $(0.0459)$ \\
KNOW & $-0.103 * *$ \\
EDU & $(0.0500)$ \\
& $-0.0677^{* *}$ \\
AGE & $(0.0305)$ \\
GENDER & 0.0118 \\
& $(0.0351)$ \\
Controls & 0.000523 \\
$R^{2}$ & $(0.0375)$ \\
$N$ & 0.00650 \\
& $(0.0332)$ \\
\hline
\end{tabular}

Note: The table shows OLS estimated coefficients and standard errors in brackets. Significance levels are $10 \%(*)$, $5 \%(* *)$ and $1 \%(* *)$. Change is the absolute difference of each person's probability to choose a GM bread before and after the information sheet. The coefficients are standardised ( $z$-scores) and directly comparable.

Our final set of results comes from a LCL. This model has its clear limitations (e.g. less heterogeneity modelled) but also simplifies the estimations in an informative way by grouping the consumers into latent classes. To determine the number of classes (groups), we used Akaike's information criterion (AIC) and Bayesian information criterion (BIC), which improved with each additional class we included. However, the more classes we tried to estimate, the more often we ran into convergence issues and we often obtained at least one class with implausible preferences. Thus, we settled with the simplest model with only two classes.

The first class includes 24 per cent of the respondents, the second class 76 per cent. Regarding consumer characteristics, the first class is more likely to take nutritional supplements (a proxy for health-consciousness), be more educated and be older. Regarding their preferences, the first class has no positive WTP for GM bread and has a strong preference for organic bread. Class 2, has a positive WTP for GM bread but it is much lower than that for other bread. This class prefers conventional bread. However, in contrast to class 1 , these consumers do respond positively to the added functional attributes of the GM bread. 
Table 12. Latent class analysis

\begin{tabular}{|c|c|c|}
\hline & WTP Class 1 & WTP Class 2 \\
\hline Share $(\%)$ & 0.243 & 0.757 \\
\hline GM & $\begin{array}{c}-0.0185 \\
(0.804)\end{array}$ & $\begin{array}{l}2.227 * * * \\
(0.245)\end{array}$ \\
\hline Conventional & $\begin{array}{l}2.509 * * * \\
(0.478)\end{array}$ & $\begin{array}{l}3.605 * * * \\
(0.226)\end{array}$ \\
\hline Organic & $\begin{array}{l}5.513 * * * \\
(1.132)\end{array}$ & $\begin{array}{l}2.969 * * * \\
(0.244)\end{array}$ \\
\hline Shelf-life & $\begin{array}{c}1.184 \\
(0.919)\end{array}$ & $\begin{array}{l}0.562 * * * \\
(0.154)\end{array}$ \\
\hline Nutrients & $\begin{array}{c}-1.117 \\
(1.330)\end{array}$ & $\begin{array}{l}0.458 * * * \\
(0.160)\end{array}$ \\
\hline Fibre & $\begin{array}{c}0.238 \\
(0.463)\end{array}$ & $\begin{array}{c}0.193 * * \\
(0.0793)\end{array}$ \\
\hline Bakery & $\begin{array}{l}1.006 \text { *** } \\
(0.169)\end{array}$ & $\begin{array}{l}0.778 * * * \\
(0.0674)\end{array}$ \\
\hline Whole wheat & $\begin{array}{l}0.462 * * * \\
(0.0924)\end{array}$ & $\begin{array}{l}0.191 * * * \\
(0.0333)\end{array}$ \\
\hline Supplement & $\begin{array}{c}0.283^{*} \\
(0.157)\end{array}$ & \\
\hline Edu & $\begin{array}{c}0.229 * \\
(0.125)\end{array}$ & \\
\hline Age & $\begin{array}{l}0.384 * * * \\
(0.0943)\end{array}$ & \\
\hline Gender & $\begin{array}{c}-0.198 \\
(0.135) \\
\end{array}$ & \\
\hline pseudo $R^{2}$ & 0.24 & \\
\hline AIC & $6,767.0$ & \\
\hline BIC & $6,938.4$ & \\
\hline$N$ & 12,704 & \\
\hline
\end{tabular}

Note: The table shows latent class estimated coefficients and standard errors in brackets. Significance levels are $10 \%(*), 5 \%(* *)$ and $1 \%(* * *)$. The coefficients express the WTP for the attributes. Class 2 is the reference.

\section{Discussion and conclusion}

The literature on the effect of information and knowledge on GM acceptance is inconclusive as some studies find a positive relationship and others find a negative relationship. As discussed by House et al. (2005), an important issue is that studies have sometimes used self-reported knowledge whereas other have used measured knowledge. This explains part of the variation in research findings. Another important reason for inconclusive information effects is the preferences themselves, as theory predicts information to improve the match between preferences and choices, leading to country- and 
culture-specific effects. A final issue is endogeneity. The amount of information somebody has about GM is plausibly as much affected by this person's attitudes as the other way round. Studies in which consumers were experimentally provided with balanced information usually find a negative effect on attitudes and no significant behavioural effect (Rousu et al. 2002; Scholderer and Frewer, 2003). We add an analysis of the effect of experimentally provided information on those initially more open to GM, those more opposed and also on those with more or less knowledge. The first part of our main result is that consumers who were initially less opposed to GM bread became slightly more opposed after receiving more information. Those who were initially more opposed to GM did not significantly respond to our information. Furthermore, consumers who could answer more knowledge questions correctly were less likely to have any positive WTP for GM bread and they were less likely to change their mind in response to additional information. Overall, the 'market shares' in our CE did not change in response to our provided information. This is the second part of our main result: the effect of information is generally very small.

The observation that balanced information only had a small, negative effect on initially less GM opposed consumers is consistent with three interpretations: first, the German consumers who are less opposed to GM could especially be those who are not aware of potential risks, whereas consumers who are more opposed are mostly those with a sufficient understanding to make an informed choice. Second, the German consumers who are more GM averse could have preferences that are not based on factual information (but e.g. on emotions or strong convictions) and this is the reason why additional information has no effect on them. Third, German consumers might be generalised Bayesian learners, who do update their beliefs in response to new information but often slower than standard Bayesians (Just, 2002). Our finding that the more GM averse consumers, who do not change their mind, are the ones who are more educated and knowledgeable seems most consistent with the first interpretation. The most plausible explanation for our findings is that even though German consumers generally do not know much about GM technology, they know enough to make an informed consumption decision. Thus, most German consumers do not want to consume bread made out of GM wheat and this is a reflection of their preferences. We do not find any signs of confirmatory bias (i.e. consumers who are initially less opposed becoming even less opposed from balanced information and consumers who are initially more opposed becoming even more opposed).

This suggests that information campaigns for or against GM food, which are often suggested by proponents and enemies of GM crops alike, would only have a very limited effect on German consumers' attitudes. Our findings also have implications for the economic modelling and simulation of the welfare effects of different policies. To adequately model the effect of consumer aversion against GM foods on consumer and producer welfare, trade and other outcomes, it is important to understand preference heterogeneity and its sources. We find that preference heterogeneity is almost unaffected by 
differences in information and knowledge in Germany and, if at all, an increase in these factors would make preferences more homogenous and GM averse. In contrast to previous studies, we have increased the attractiveness of the GM bread by making it functional as we added benefits such as an increase in shelf-life, added nutrients or fibre. This is a direct test of the view that aversion to GM food technology might be explained by a lack of consumer benefit(s). We find that these added benefits only matter for consumers who are less averse to GM food technology.

Methodologically, it is important to distinguish preference heterogeneity from scale heterogeneity. Scale heterogeneity arises if some respondents choose more randomly and others more deterministically (Fiebig et al. 2010). As Rigby and Burton (2005) show, it is important to take into account preference heterogeneity. However, the frameworks currently used for this - the mixed logit and the latent class model - potentially confound preference and scale heterogeneity when both exist. In this study, we mostly relied on GMNL, which can distinguish between both kinds of heterogeneity and both are statistically significant at any conventional level. However, even though we find that it improves data-fit, we do not get qualitatively distinct results compared to simpler frameworks that cannot.

As general information about German consumer attitudes towards GM, we find that despite the generally observed aversion, the 'market share' of GM bread in our experiment reached 16 per cent. Using a latent class model, we even find that a considerable share of the consumers has a positive (even though low) WTP for GM bread. Thus, if GM bread were allowed, there could be a niche market. It should be noted that our results suggest that these consumers know a little less about GM and become a little more critical once they receive more information, but this learning effect is very small. The larger concern for companies would perhaps be the comparably low WTP, which might reduce profitability.

We would finally like to point out some limitations of our study and where there is potential for future research. The most prominent limitation of our study design is dynamic hypothetical bias, which arises because we conducted our $\mathrm{CE}$ in a specific point in time without allowing for longer term learning and adaptation (Araña and León, 2013). Thus, we do not know how market shares of GM bread would develop over time, if German consumers could actually buy it. The reason is that, in contrast to our one-off CE, there would probably be learning and social interactions, which would introduce a dynamic element to preferences and attitudes. The other important limitation of our study is its sample. We base our study on consumer in the Munich metropolitan area, where the population is above average educated and economically well off (compared to the rest of Germany and also Europe) and we further over-sampled younger and better educated consumers. In our GMNL framework, this is unlikely to play an important role, especially for our main research questions whether initial attitudes and knowledge affect how consumers respond to balanced information about GM technology. It is well known that estimated, conditional choice probabilities are unaffected by 
the sampling scheme but the constants are biased when not interacted (Manski and Lerman, 1977). Since we are analysing interacted constants in our study, we do not need to worry about a selection bias (Nizalova and Murtazashvili, 2016). However, the estimated class shares in our latent class approach and our descriptive statistics, including all market shares, must be treated with caution. A replication study in a different part of Germany could perhaps clarify the generality of our findings.

Overall, the very limited response to balanced information suggests that either consumers' beliefs about GM are sufficiently informed to match revealed preferences to actual preferences or there is a lack of learning despite revealed and actual preferences not matching. The former would be more consistent with standard economic theory, the latter more with an 'anomaly' from behavioural economics. A further investigation of the mechanism(s) behind our finding(s) seems a promising avenue for future research. Finally, it could also be interesting to ask consumers directly what kind of information would have an impact on their behaviour and what would increase/decrease the probability that they would choose a GM food product. This would allow to then test whether information about the mentioned attributes or changes to the presented GM food product would actually make a difference for consumption choices.

\section{Supplementary data}

Supplementary data are available at European Review of Agricultural Economics online.

\section{References}

Araña, J. E. and León, C. J. (2013). Dynamic hypothetical bias in discrete choice experiments: evidence from measuring the impact of corporate social responsibility on consumers' demand. Ecological Economics 87: 53-61.

Baker, G. A. and Burnham, T. A. (2001). Consumer response to genetically modified foods: market segment analysis and implications for producers and policy makers. Journal of Agricultural and Resource Economics 26: 387-403.

Bech, M. and Gyrd-Hansen, D. (2005). Effects coding in discrete choice experiments. Health Economics 14: 1079-1083.

Boccaletti, S. and Moro, D. (2000). Consumer willingness-to-pay for GM food products in Italy. AgBioForum 3: 259-267.

Borg, S., Brinch-Pedersen, H., Tauris, B., Madsen, L. H., Darbani, B., Noeparvar, S. and Holm, P. B. (2012). Wheat ferritins: improving the iron content of the wheat grain. Journal of Cereal Science 56: 204-213.

Bundesministerium für Ernährung und Landwirtschaft. (2016). Grüne Gentechnik. Retrieved January 01, 2017, from https://www.bmel.de/DE/Landwirtschaft/Pflanzenbau/Gentechnik/_ Texte/NatRegelungAnbauverbote.html; jsessionid=82638DE687B1BFCDBD3931ECE91466B7. 2_cid358\#doc5232776bodyText2. 
Butkowski, O. K., Pakseresht, A., Lagerkvist, C. J. and Bröring, S. (2017). Debunking the myth of general consumer rejection of green genetic engineering: empirical evidence from Germany. International Journal of Consumer Studies 41: 723-734.

Carlsson, F., Frykblom, P. and Lagerkvist, C. J. (2005). Using cheap talk as a test of validity in choice experiments. Economics Letters 89: 147-152.

Carlsson, F. and Martinsson, P. (2008). How much is too much? Environmental and Resource Economics 40: 165-176.

Carlsson, F., Mørkbak, M. R. and Olsen, S. B. (2012). The first time is the hardest: a test of ordering effects in choice experiments. Journal of Choice Modelling 5: 19-37.

Christoph, I. B., Bruhn, M. and Roosen, J. (2008). Knowledge, attitudes towards and acceptability of genetic modification in Germany. Appetite 51: 58-68.

Costa-Font, M., José, M. G. and Traill, W. B. (2008). Consumer acceptance, valuation of and attitudes towards genetically modified food: review and implications for food policy. Food Policy 33: 99-111.

Costa-Font, J. and Mossialos, E. (2007). Are perceptions of 'risks' and 'benefits' of genetically modified food (in) dependent? Food Quality and Preference 18: 173-182.

Cuite, C. L., Helen, L. A. and William, K. H. (2005). An empirical investigation of the role of knowledge in public opinion about GM food. International Journal of Biotechnology 7: 178-194.

Daly, A., Dekker, T. and Hess, S. (2016). Dummy coding vs effects coding for categorical variables: clarifications and extensions. Journal of Choice Modelling 21: 36-41.

De Steur, H., Blancquaert, D., Strobbe, S., Lambert, W., Gellynck, X. and Van Der Straeten, D. (2015). Status and market potential of transgenic biofortified crops. Nature Biotechnology 33(1): 25-29.

de Vendômois, J. S., Roullier, F., Cellier, D. and Séralini, G.-E. (2009). A comparison of the effects of three GM corn varieties on mammalian health. International Journal of Biological Sciences 5(7): 706-726.

Depositario, D. P. T., Nayga, R. M., Jr, Wu, X. and Laude, T. P. (2009). Effects of information on consumers' willingness to pay for Golden Rice. Asian Economic Journal 23: 457-476.

Emberger-Klein, A., Zapilko, M. and Menrad, K. (2016). Consumers' preference heterogeneity for GM and organic food products in Germany. Agribusiness 32: 203-221.

Fiebig, D. G., Michael, P. K., Louviere, J. and Wasi, N. (2010). The generalized multinomial logit model: accounting for scale and coefficient heterogeneity. Marketing Science 29: 393-421.

Food and Agricultural Organization (2004). The State of Food and Agriculture. Italy: Food and Agricultural Organization.

Forsa (2014). Kulturelle Wünsche der Verbraucher bei der Auswahl ihrer Lebensmittel Ergebnisse einer internationalen Umfrage. Berlin: forsa main Marktinformationssysteme $\mathrm{GmbH}$.

Frewer, L. J., van der Lans, I. A., Fischer, A. R., Reinders, M. J., Menozzi, D., Zhang, X. and Zimmermann, K. L. (2013). Public perceptions of agri-food applications of genetic modification - a systematic review and meta-analysis. Trends in Food Science \& Technology 30: 142-152.

Gaskell, G., Stares, S., Allansdottir, A., Allum, N., Castro, P., Esmer, Y., Fischler, C., Jackson, J., Kronberger, N. and Hampel, J. 2010. 'Europeans and Biotechnology in 2010 Winds of change?'. Brussels: European Commission.

Hanley, N., Adamowicz, W. and Wright, R. E. (2005). Price vector effects in choice experiments: an empirical test. Resource and Energy Economics 27: 227-234.

Hensher, D. A., Rose, J. M. and Greene, W. H. (2010). Applied Choice Analysis: A Primer. Cambridge: Cambridge University Press. 
Hensher, D. A., Rose, J. M. and Greene, W. H. (2015). Applied Choice Analysis: A Primer. Cambridge: Cambridge University Press.

Hess, S., Lagerkvist, C. J., Redekop, W. and Pakseresht, A. (2016). Consumers' evaluation of biotechnologically modified food products: new evidence from a meta-survey. European Review of Agricultural Economics 43: 703-736.

House, L., Lusk, J., Jaeger, S., Traill, W. B., Moore, M., Valli, C., Morrow, B. and Yee, W. M. S. 2005. Objective and subjective knowledge: Impacts on consumer demand for genetically modified foods in the United States and the European Union. AgBioForum 7: 113-123.

Huffman, W. E. and Rousu, M. (2006). Consumer attitudes and market resistance to biotech products. In: R. E. Just, J. M. Alston and D. Zilberman (eds), Regulating Agricultural Biotechnology: Economics and Policy. New York: Springer Science+Business Media, LLC, 200-240.

Ison, J. and Kontoleon, A. 2014. Consumer preferences for functional GM foods in the UK: a choice experiment. AgBioForum 17: 28-36.

James, C. (2010). Global Status of Commercialized Biotech/GM Crops: 2010. ISAAA Brief No. 42. Ithaca, NY: International Service for the Acquisition of Agri-Biotech Applications.

James, C. (2014). Global Status of Commercialized Biotech/GM Crops: 2014. Ithaca, NY: ISAAA.

Jonas, D. A., Elmadfa, I., Engel, K. H., Heller, K., Kozianowski, G., König, A., Muller, D., Narbonne, J. F., Wackernagel, W. and Kleiner, J. (2001). Safety considerations of DNA in food. Annals of Nutrition \& Metabolism 45: 235-254. www.karger.com/ journals/anm

Just, D. R. (2002). Information, processing capacity, and judgment bias in risk assessment. In: R. E. Just and R. D. Pope (eds), A Comprehensive Assessment of the Role of Risk in U.S. Agriculture. Norwell, MA: Kluwer.

Louviere, J., Street, D., Carson, R., Ainslie, A., Deshazo, J., Cameron, T. and Marley, T. (2002). Dissecting the random component of utility. Marketing letters 13(3): 177-193.

Louviere, J. J., Hensher, D. A. and Swait, J. D. 2000. Stated Choice Methods: Analysis and Applications. New York: Cambridge University Press.

Lusk, J. L., House, L. O., Valli, C., Jaeger, S. R., Moore, M., Morrow, J. L. and Traill, W. B. (2004). Effect of information about benefits of biotechnology on consumer acceptance of genetically modified food: evidence from experimental auctions in the United States, England, and France. European Review of Agricultural Economics 31: 179-204.

Lusk, J. L., Jamal, M., Kurlander, L., Roucan, M. and Taulman, L. (2005). A metaanalysis of genetically modified food valuation studies. Journal of Agricultural and Resource Economics 28-44.

Lusk, J. L. and Norwood, F. B. (2005). Effect of experimental design on choice-based conjoint valuation estimates. American Journal of Agricultural Economics 87: 771-785.

Lusk, J. L., Schroeder, T. C. and Tonsor, G. T. (2014). Distinguishing beliefs from preferences in food choice. European Review of Agricultural Economics 41: 627-655.

Manski, C. F. (2004). Measuring expectations. Econometrica: Journal of the Econometric Society 72: 1329-1376.

Manski, C. F. and Lerman, S. R. (1977). The estimation of choice probabilities from choice based samples. Econometrica: Journal of the Econometric Society 45: 1977-1988.

McCluskey, J. J., Grimsrud, K. M., Ouchi, H. and Wahl, T. I. (2003). Consumer response to genetically modified food products in Japan. Agricultural and Resource Economics Review 32: 222-231. 
McFadden, D. (1973). Conditional logit analysis of qualitative choice behavior. In: P. Zarembka (ed.), Frontiers in Econometrics. New York: Academic Press, 105-142.

McFadden, B. R. and Lusk, J. L. (2015). Cognitive biases in the assimilation of scientific information on global warming and genetically modified food. Food Policy 54: 35-43.

Moon, W. and Balasubramanian, S. K. (2001). Public perceptions and willingness to pay a premium for NonGM foods in the U.S. and UK. AgBioForum 4: 221-231.

Niederhuber, M. (2015). Insecticidal Plants: The Tech and Safety of GM Bt Crops. Retrieved from http://sitn.hms.harvard.edu/flash/2015/insecticidal-plants/ (accessed January 2017).

Nizalova, O. Y. and Murtazashvili, I. (2016). Exogenous treatment and endogenous factors: vanishing of omitted variable bias on the interaction term. Journal of Econometric Methods 5: 71-77.

Onyango, B., Schilling, B. and Nayga, R. M., Jr. (2004). Role of product benefits and potential risks in consumer acceptance of genetically modified foods. AgBioForum 7(4): 202-211.

Rabin, M. (1998). Psychology and economics. Journal of Economic Literature 36: 11-46.

Rabin, M. and Schrag, J. L. (1999). First impressions matter: a model of confirmatory bias. The Quarterly Journal of Economics 114: 37-82.

Ratcliffe, J. (2000). The use of conjoint analysis to elicit willingness-to-pay values: proceed with caution? International Journal of Technology Assessment in Health Care 16: $270-290$.

Reed Johnson, F., Lancsar, E., Marshall, D., Kilambi, V., Mühlbacher, A., Regier, D. A. and Bridges, J. F. P. (2013). Constructing experimental designs for discrete-choice experiments: report of the ISPOR conjoint analysis experimental design good research practices task force. Value in Health 16(1): 3-13. doi:10.1016/j.jval.2012.08.2223.

Revelt, D. and Train, K. (2000). Customer specific taste parameters and the mixed logit: Households' choice of electricity supplier. Working Paper E00-274, University of California, Berkeley.

Rigby, D. and Burton, M. (2005). Preference heterogeneity and GM food in the UK. European Review of Agricultural Economics 32: 269-288.

Rousu, M., Huffman, W., Shogren, J. F. and Tegene, A. 2002. 'The value of verifiable information in a controversial market: evidence from lab auctions of genetically modified food', Working Paper.

Scarpa, R., Gilbride, T. J., Campbell, D. and Hensher, D. A. (2009a). Modelling attribute non-attendance in choice experiments for rural landscape valuation. European Review of Agricultural Economics 36: 151-174.

Scarpa, R., Gilbride, T. J., Campbell, D. and Hensher, D. A. (2009b). Modelling attribute non-attendance in choice experiments for rural landscape valuation. European Review of Agricultural Economics 36: 151-174.

Scarpa, R., Zanoli, R., Bruschi, V. and Naspetti, S. (2012). Inferred and stated attribute non-attendance in food choice experiments. American Journal of Agricultural Economics 95: 165-180.

Scholderer, J. and Frewer, L. J. (2003). The biotechnology communication paradox: experimental evidence and the need for a new strategy. Journal of Consumer Policy 26: $125-157$.

Springer, A., Mattas, K., Papastefanou, G. and Tsioumanis, A. (2002). Comparing Consumer Attitudes Towards Genetically Modified Food in Europe. Spain: Zaragoza, 28-31. August. 
Tang, G., Qin, J., Dolnikowski, G., Russell, R. and Grusak, M. (2009). Golden Rice is an effective source of vitamin A. The American Journal of Clinical Nutrition 89: $1776-1783$.

Trabalza-Marinucci, M., Brandi, G., Rondini, C., Avellini, L., Giammarini, C., Costarelli, S. and Magnani, M. (2008). A three-year longitudinal study on the effects of a diet containing genetically modified Bt176 maize on the health status and performance of sheep. Livestock Science 113(2-3): 178-190.

Train, K. E. 2003. Discrete Choice Methods with Simulation. New York, NY: Cambridge University Press.

Train, K. and Weeks, M. (2005). Discrete choice models in preference space and willingto-payspace. In: R. Scarpa and A. Alberini (eds), Applications of Simulation Methods in Environ-mental and Resource Economics. Dordrecht, The Netherlands: Springer Publisher, 1-16 (Chapter 1).

United States Department of Agriculture. (2016). Background. Retrieved January 01, 2017, from https://www.ers.usda.gov/topics/crops/wheat/background/.

Viney, R., Savage, E. and Louviere, J. (2005). Empirical investigation of experimental design properties of discrete choice experiments in health care. Health Economics 14(4): 349-362.

World Health Organization (2014). Frequently asked questions on genetically modified foods. Retrieved from http://www.who.int/foodsafety/areas_work/food-technology/faqgenetically-modified-food/en/ (accessed January 2017).

Wuepper, D. (2017). What is the value of world heritage status for a German national park? A choice experiment from Jasmund, 1 year after inscription. Tourism Economics 23: 1114-1123.

Wunderlich, S. and Gatto, K. A. (2015). Consumer perception of genetically modified organisms and sources of information. Advances in Nutrition 6: 842-851. 